\title{
Choices for life: how can we help?
}

\author{
Ana Farinha ${ }^{1}$ \\ ${ }^{1}$ Nephrology department, Centro Hospitalar de Setúbal, Setúbal, Portugal
}

\begin{abstract}
"May your choices reflect your hopes, not your fears".
\end{abstract}
Nelson Mandela

\section{HISTORICAL CONTEXT}

Fifty years ago, Portugal lived under a dictatorship. A significant number of people were illiterate and there was no health care system to support the sick. Since then, a long road has been traveled in medical care: Serviço Nacional de Saúde (the National Health Service) has been created, medicine has evolved, and brand-new treatments are available for all kind of patients, including dialysis for elderly and frail ones. The spread of resources has not been followed by literacy in health, meaning doctors start to choose for their patients, who blindly believe them.

\section{PRINCIPLES OF BIOMEDICAL ETHICS}

In 1977, Thomas Beauchamp and James Childress developed the Principles of Biomedical Ethics ${ }^{1}$ that now guide medical clinical practice. Autonomy, beneficence, nonmaleficence and justice are the four pillars of modern medicine...in theory. But the concepts of beneficence and nonmaleficence may not be clearly black and white. No doctor offers dialysis if he does not believe it is the best option. Otherwise, not offering it would be denying treatment. Yet, for the same patient, it is possible that another colleague would recommend Conservative Care to respect the principle of nonmaleficence in an elderly frail patient. The same patient, in the same scenario, may have two completely different opinions based on the nephrologist's experience, on personal beliefs, on the lack of accuracy in prognostic tools or even based on institutional policies and resources. Autonomy refers to self-determination for free choices and is the fundament of informed consent. Nevertheless, there are several ways autonomy can be limited. Pain, fear, economic dependence, and manipulation are all forms of restraint on freewill.

\section{CHOOSING END STAGE KIDNEY DISEASE THERAPY}

In nephrology, end stage kidney disease (ESKD) treatment options are a pinnacle of how bioethical principles are respected in Portugal. In 2011 a guideline from Direção Geral de Saúde ${ }^{2}$ established the obligation to present kidney replacement therapy (KRT) options to all stage 4 to 5 CKD patients. The purpose of this guideline is remarkable: to establish the need to enlighten all patients about their condition and present them with all options, including Conservative Care. The document is divided into two parts: the first is dedicated to nephrologists, where the fundaments and framework for each KRT are presented and the second is provided to patients as information to help them choose an option - a patient decision aid (PtDA).

PtDA are tools or interventions that support shared decision-making. They come in several formats: written information, oral presentations, podcasts, videos or web resources. Analyses of these different options - their benefits and limitations - are barely found ${ }^{3}$. Further, they depend heavily on social and cultural issues. In Portugal, the guideline demands that a total of 17 pages should be supplied during an outpatient appointment where KRT is discussed. The model of this appointment varies from center to center but the brochure provided is standardized. But after all, are these 17 pages of full information really helpful for decision making? Most of our incident dialysis patients are elderly, with significant geriatric syndromes such as impaired vision or hearing, cognitive dysfunction, and social, familiar or economic constraints that hamper the ability to realize and benefit from these extensive tools. Informed consent cannot be simplified to dump all possible information (risks, advantages) that doctors are aware of. Most of our patients are not doctors, so they won't be able to digest all this information. Informed consent must be elevated to a provision of adequate information that patients may understand, allowing them to choose which option will help them attain their goals.

The way this information is provided has been widely studied in CKD patients by Keren Ladin et al. ${ }^{4,5}$ She identified four distinct approaches:

- Paternalistic (the physician acts as a patient guardian and uses his expertise to choose for the patient);

- Informative (the physician is the holder of technical information that is provided to the patient who decides, with no influence of doctor's opinion);

- Interpretive (the physician exploits the patient's goals and based on them, guides him to treatment choice that may fit better with his values. It relies on a truly shared responsibility where doctors translate medical information into patient wishes);

- Institutionalist (information provided is influenced by institutional guidelines and norms). 
All these models have strengths and limitations: the paternalistic model may be adequate in an emergency situation where there is no time for opportune discussions. The informative model may be suitable for patients who have high health literacy and where influences should be excluded. For our elderly patients, a more person-centered care may be more appropriate. The problem of the interpretative model is that it requires skills that are not usually taught in residency, such as communication, and it is time-consuming.

Dr. Atul Gawande, an American surgeon dedicated to end-of-life care, who is also an adviser of the Conversation Project (a plan to help people share their wishes for care through the end of life) writes "We think our job is to ensure health and survival. But really, it is larger than that. It is to enable well-being. And well-being is about the reasons one wants to live." In his most cited bestseller Being Mortal ${ }^{6}$, he also discusses the above models of communication. He stresses that the paternalistic model is the most commonly used in "vulnerable patients - the frail, the poor, the elderly, and anyone else who tends to do what they're told". He also highlights that patients "want information and control, but [they] also want guidance". And suggests how to do it: "doctor's role is to help patients determine what they want. (...) What is most important to you? What are your worries? Then, when they know [patients'] answers, they tell [them] about the red pill and the blue pill and which one would most help achieve [patients'] priorities".

So, in addition to the content of the information, its format matters. In other words, choosing ESKD therapy must be a person-centered care
(PCC). PCC is defined by the Institute of Medicine as a care that responds to individual patient needs and values and guides treatment decisions ${ }^{13}$ Eight principles are generally recognized (Figure 1$)^{14}$. Respect for patient preferences, information and education are some of the most important which are regularly mentioned and supported by all guidelines and recommendations from nephrology societies ${ }^{2,7-10}$. Even so, the fact is that it is not widely implemented. There are several barriers ${ }^{11,12}$ to that:

- Patient barriers (illiteracy in health, limited access or motivation to search for information, analphabetism, blindness, deafness, cognitive impairment, lack of familiar support...);

- Doctors' barriers (time constraints, lack of confidence in discussing end-of-life conversations..);

- System barriers (limited incentives to education, lack of support, lack of human or logistic resources,...).

Some of these barriers are for us, nephrologists, to beat and settle the requirements to a true shared decision-making process.

\section{BASIC CONTENTS OF A DECISION-MAKING APPROACH IN CLINICAL PRACTICE}

In clinical practice, guiding CKD patients in a Decision-Making Process starts with the selection of who should be approached and when. It

\section{Figure 1}

Picker's Eight Principles of Patient-Centered Care

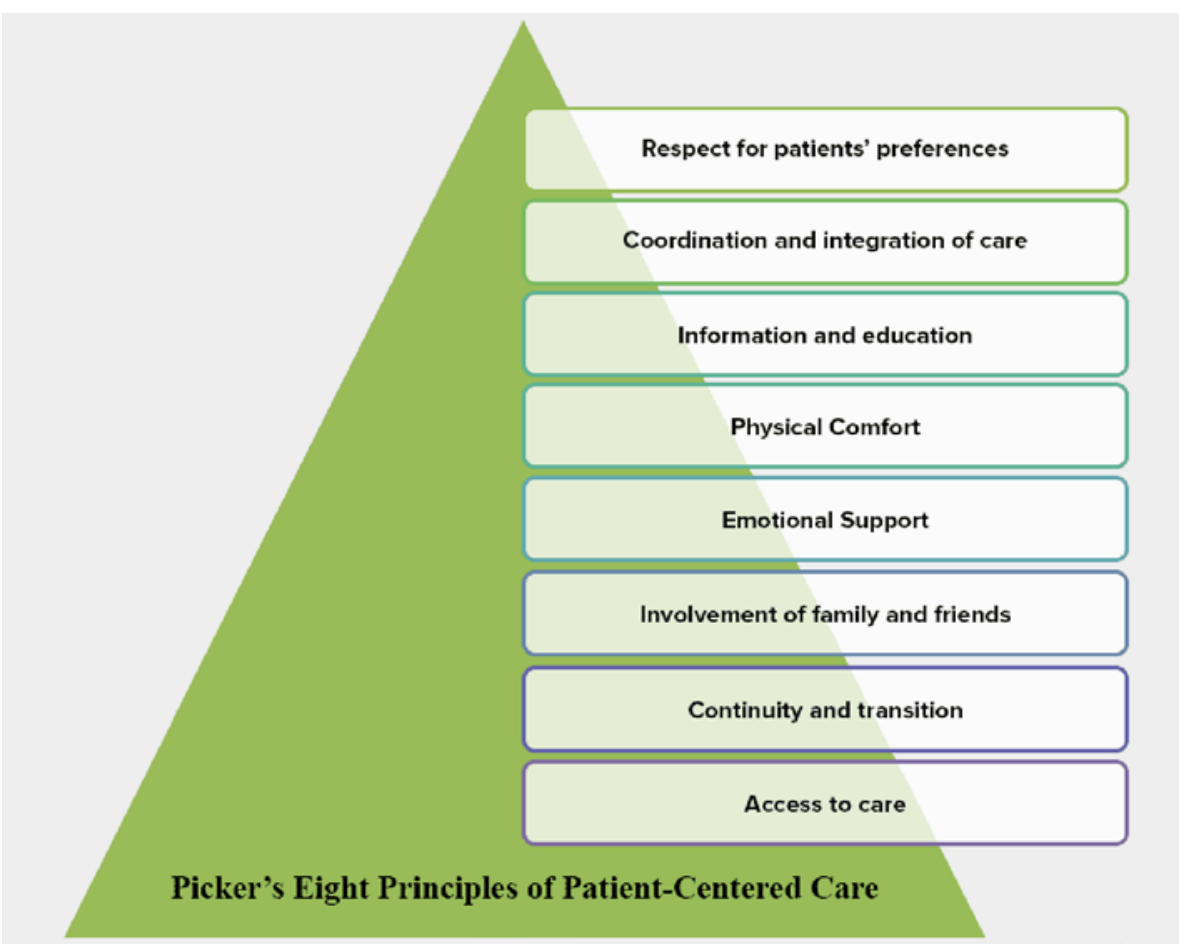




\section{Table 1}

Basic contents of a pre-dialysis education program

Basic contents of a pre-dialysis education program
1. Basic knowledge of kidney function
2. Impact of CKD in health
3. Symptoms of kidney insufficiency
4. Prognosis for the specific patient with its conditions and comorbidities (a)
5. Disease trajectory in each modality
6. Expected quality of life and functional status in each modality
7. Particularities for each KRT
- need to travel
- need for surgery
- flexibility to time control
8. Nutritional lessons
9. Social and economic support for patient and caregiver
10. Psychological support for patient and caregiver
11. Global geriatric assessment for elderly or dependent patients (b)
12. Group support and/or real sessions with other patients

(a) Farinha, A. Prognostication in End-Stage Renal Disease. Port J Nephrol Hypert 2016; 30(4): 246-251 (b) Farinha, A; Duque, S. Comprehensive geriatric assessment in nephrology. Port J Nephrol Hypert 2019; 33(3): 168-175

might seem a very basic question: all patients in CKD stage 4 should be informed about KRT. But if this is clear for young patients, it might not be so evident for elderly patients. We should not forget that they have a competitive risk of dying sometimes bigger than reaching ESKD. Discussing these issues too soon may anticipate a dark fate that might never come. It would create anxiety and waste of precious resources ${ }^{15}$. Timing for discussing KRT in elderly is discussed elsewhere ${ }^{7}$. In terms of how to do it, there are three aspects that I believe are fundamental:

1. Format in which the information is provided (as mentioned above, which patient decision aid is more suitable for each patient and family);

2. Content of the information and adequacy / individualization of it;

3. Number of sessions to provide all the information required.
The ideal pathway to choose KRT should start with patient education. A formal and structured program to raise awareness of the disease, its consequences and options is fundamental (Table 1$)^{16}$. To approach all these issues, the team should be multidisciplinary. In addition to a nephrologist, nurse and nutritionist, a social worker to make clear patients' rights and social support is also required, as is a psychotherapist. The formats in which all these questions are addressed are as important as the content. It is not worth providing the most complete information if the patient cannot understand it. A peer session or support group, with other patients sharing their experiences, may be more useful than all other information provided. In times of pandemic such as we are living, social distancing may require other options, such as videotapes of patients contributing with their own experiences, but the importance of 'testimony from people who are in the same boat should not be neglected. In a specific article that analyses pre-dialysis education programs, those with a single session were excluded, from the beginning because they didn't meet the minimum requirements ${ }^{17}$. The fact that education is a time-consuming task should not be an obstacle, as long as nephrologists realize its importance. If we believe it is necessary to educate patients to reach objective parameters such as blood pressure which are easy to measure ${ }^{18}$ we should not forget that education programs may impact something bigger: patient-related outcomes, or in other words - well living!

Finally, pre-dialysis programs are also the appropriate moment to discuss advance care planning. In Portugal, living will has been available for about 10 years ${ }^{19}$, but by last year, fewer than 30,000 persons had made a living will. This reflects illiteracy in health, but also physicians' reluctance to have end-of-life discussions.

\section{HARD CHOICES AND COMMUNICATION SKILLS}

That is why, in addition to patient education, patient-centered care requires physicians' education. One of the most important barriers to provide it is lack of communication skills. In Anglo-Saxon countries, where patient-centered decisions are more implemented, doctors have training in communication so they can guide patients through difficult options. There are several available resources that are useful

\section{Table 2}

SPIKES framework and example - How to break bad news

\begin{tabular}{|c|c|c|}
\hline Framework & Meaning & Example \\
\hline Set up the interview & $\begin{array}{l}\text { Arrange a place where conversation would not be interrupted } \\
\text { Prepare yourself with all the information you can get on patient's clinical situation. }\end{array}$ & $\begin{array}{l}\text { Can I talk to you about your situation? When is it best for you and your } \\
\text { family? }\end{array}$ \\
\hline Perception assessment & $\begin{array}{l}\text { Assess patient understanding about his situation } \\
\text { Determine patient level of comprehension }\end{array}$ & What has already been told to you about your situation? \\
\hline Invitation & Ask the patient what information he wants to know & Is that okay if I talk to you more about your condition? \\
\hline $\begin{array}{l}\text { Knowledge and } \\
\text { information provision }\end{array}$ & $\begin{array}{l}\text { Provide medical facts in an intelligible language: consider educational, socio- } \\
\text {-economic and cultural background } \\
\text { Check patient comprehension of what you said }\end{array}$ & $\begin{array}{l}\text { I am afraid your kidneys are not working anymore. Do you understand } \\
\text { what that means? }\end{array}$ \\
\hline $\begin{array}{l}\text { Address patients' } \\
\text { Emotions with } \\
\text { Empathic responses }\end{array}$ & $\begin{array}{l}\text { Identify patient's emotions and be emphatic to them. Give the patient time } \\
\text { to express his feelings, even in silence. }\end{array}$ & I believe it is very difficult to hear this. How do you feel about it? \\
\hline $\begin{array}{l}\text { Strategize and } \\
\text { Summarize }\end{array}$ & $\begin{array}{l}\text { Summarize information. Ask patient if he wants any other information. } \\
\text { Schedule next meeting and offer your support. }\end{array}$ & $\begin{array}{l}\text { It is a lot to deal today. For now we will (establish the plan). We will check } \\
\text { in our next appointment how it's going for you. }\end{array}$ \\
\hline
\end{tabular}


to help clinicians in these activities. There are also websites which present them in an accessible way, such as tutorials where examples can be followed ${ }^{20,21}$. I am familiar with some of them that I consider really valuable in clinical practice.

SPIKES (Table 2) is a useful tool to break bad news ${ }^{22}$. It might be used when patients come to the KRT appointment to set up the patient comprehension of the situation and to further establish a plan. As stated in this article, the healthcare team should not only provide information but also build insight on the best modality that serves the patient's wishes and goals. The ideal way to recognize these goals is also using structured tools. The REMAP framework (Table 3) provides a mnemonic that help clinicians to start these conversations, discussing prognosis, exploring patient values, attending emotions, and then using this information to develop the final plan. It helps doctors to enroll information in an interpretative model. Whenever a patient is undecided about the best KRT to follow, after judging benefits and limitations related to their goals, a "Best case/worst case" approach

Table 3

REMAP framework and example - How to manage a plan with the patient

\begin{tabular}{|c|c|c|}
\hline Framework & Meaning & Example \\
\hline $\begin{array}{l}\text { REFRAME the big } \\
\text { picture }\end{array}$ & $\begin{array}{l}\text { Doctor should summarize the patient's clinical situation and try to understand } \\
\text { patient's comprehension of it }\end{array}$ & $\begin{array}{l}\text { You have been suffering from CKD for a long time, also from (list other } \\
\text { serious comorbidities). I believe it has been very hard to deal with all of this. }\end{array}$ \\
\hline EXPECT emotion & Doctor should create an emphatic relation and respond to emotions & I can see how hard this is to hear. Is it okay for us to talk about what it means? \\
\hline MAP out patient values & $\begin{array}{l}\text { This is the moment to present different trajectories and elicit the patient's } \\
\text { concerns, worries and values }\end{array}$ & $\begin{array}{l}\text { Given this situation, what's most important for you? How would you like } \\
\text { to live your life from now on? }\end{array}$ \\
\hline ALIGN with values & In this step, patient's values are reviewed to aligned with the next proposals & If I have correctly understood, it sounds the most important things to you are... \\
\hline PROPOSE a plan & $\begin{array}{l}\text { The last point is to offer possible directions that match patient's goals while } \\
\text { reassuring involvement and nonabandonment. }\end{array}$ & $\begin{array}{l}\text { I think the best option to cope with your values is... because it will allow } \\
\text { you to... What do you think of this plan? }\end{array}$ \\
\hline
\end{tabular}

Figure 2

Best scenario/worst scenario approach - adapted from 21

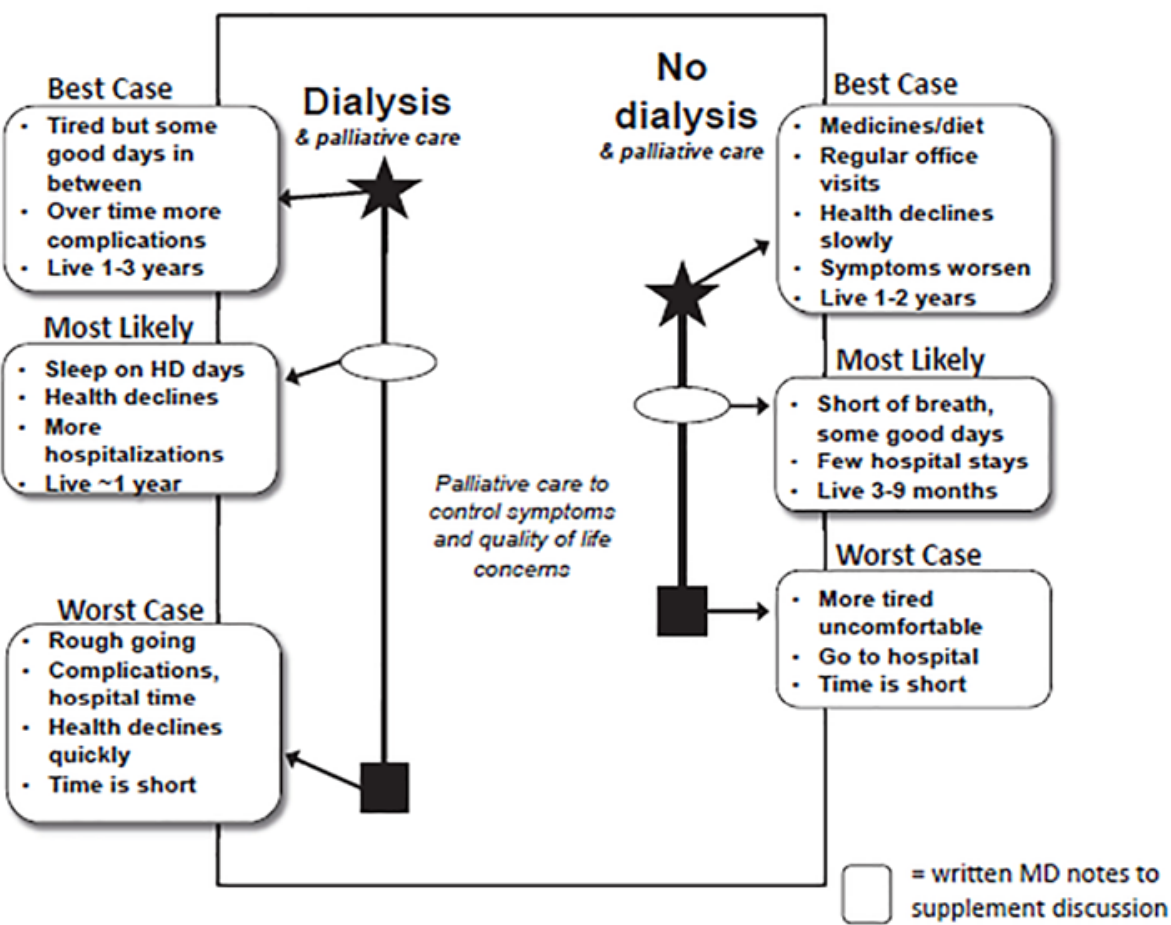

"Best Case/Worst Case" tool involves a drawing made by the physician. Each treatment option is represented by a vertical bar; the length of the bar represents the range of possible outcomes. The "best case" is represented by a star; the "worst case," by a box; and the "most likely" outcome, by an oval. The physician describes each "case" using narrative derived from clinical experience and relevant evidence and writes key points on the diagram. 
can be used ${ }^{23}$ : a personalized scheme is created (Figure 2) where the patient can visualize the best and worst scenario in each option.

\section{CONCLUSION}

These tools are not designed to decrease the responsibility to choose but to help patients to understand what fits the best into their goals of care. If we do not expect the patient to choose between classes of antidiabetics, why do we expect them to choose a modality of KRT, a treatment on which their lives will be dependent, for the rest of their days? We help patients to understand why it is important to adhere to medication. We shall help them to opt for what's best, when life is in danger. Our goal as doctors should be how to provide better care for our patients, so instead of drowning them in information that they cannot cope with, we should ask ourselves more frequently "How can we help?"

Disclosure of potential conflicts of interest: none declared.

\section{References}

1. Beauchamp TL, Childress JF. Principles of biomedical ethics. Oxford: Oxford University Press; 2001

2- https://www.dgs.pt/directrizes-da-dgs/normas-e-circulares-normativas/norma-n-0172011-de-28092011-atualizada-a-14062012-jpg.aspx. Accessed 21th june 2021.

3. Davis JL, Davison SN. Hard choices, better outcomes: a review of shared decision-making and patient decision aids around dialysis initiation and conservative kidney management. Curr Opin Nephrol Hypertens. 2017 May;26(3):205-213.

4. Ladin K, Pandya R, Perrone RD, Meyer KB, Kannam A, Loke R et al. Characterizing approaches to dialysis decision making with older adults: a qualitative study of nephrologists. Clin J Am Soc Nephrol. 2018 Aug 7;13(8):1188-1196.

5. Eilers D. Person-centered approach to deciding on long-term dialysis. Clin J Am Soc Nephrol. 2018 Aug 7;13(8):1133-1134.

6. Gawande, A. Being mortal: medicine and what matters in the end. Picador. 2014.

7. Farrington $\mathrm{K}$, Covic A, Aucella F, et al. Clinical practice guideline on management of older patients with chronic kidney disease stage $3 \mathrm{~b}$ or higher (eGFR $<45 \mathrm{~mL} / \mathrm{min} / 1.73 \mathrm{~m} 2$ ). Nephrol Dial Transplant 2016;31(2):ii1-ii66
8. Chan CT, Blankestijn PJ, Dember LM, et al. Dialysis initiation, modality choice, access, and prescription: conclusions from a Kidney Disease: Improving Global Outcomes (KDIGO) Controversies Conference. Kidney Int 2019;96(1):37-47.

9. Crail S, Walker R, Brown M, et al. Renal supportive and palliative care: position statement. Nephrology (Carlton) 2013;18(6):393-400.

10. Freidin N, O'Hare AM, Wong SPY. Person-centered care for older adults with kidney disease: core curriculum 2019. Am J Kidney Dis 2019;74(3):407-416.

11. Narva AS, Norton JM, Boulware LE. Educating patients about CKD: the path to self-management and patient-centered care. Clin J Am Soc Nephrol 2016 Apr 7;11(4):694-703.

12. Cassidy BP, Getchell LE, Harwood L, Hemmett J, Moist LM. Barriers to education and shared decision making in the chronic kidney disease population: a narrative review. Canadian J Kidney Health 2018;5:1-11

13. Epstein RM, Street RL. The values and value of patient-centered care. Ann Fam Med. 2011;9(2):100$-103$.

14. The American Geriatrics Society Expert Panel on Person-Centered Care. Person-Centered Care: A Definition and Essential Elements. J Am Geriatr Soc. 2016 Jan;64(1):15-18.

15. Valerio P, Farinha A. End stage kidney disease in the elderly: hope for the best. Port J Nephrol Hypert 2020;34(4):197-204.

16. den Bosch JV, Warren DS, Rutherford PA. Review of predialysis education programs: a need for standardization. Patient Prefer Adherence. 2015 Sep 9;9:1279-12791.

17. Teso AD, Moutet AL, Lefuel P, Seigneux S, Golay G, Martin PY. Therapeutic education program should be adapted to the specificity of chronic kidney disease. Nephrol Ther. $2019 \mathrm{Jul} ; 15(4): 193-200$.

18. Strand $H$, Parker D. Effects of multidisciplinary models of care for adult pre-dialysis patients with chronic kidney disease: a systematic review. Int J Evid Based Healthc. 2012;10:53-59.

19. https://dre.pt/application/file/a/179576. Accessed 21th june 2021.

20. http://nephro-talk.com/. Accessed 21th june 2021.

21. https://www.vitaltalk.org/resources/quick-guides/. Accessed 21th june 2021.

22. Schell JO, Cohen RA. A communication framework for dialysis decision-making for frail elderly patients. Clin J Am Soc Nephrol. 2014;9(11):2014-2021.

23. Grubbs, V. Time to recast our approach for older patients with ESRD: the best, the worst, and the most likely. Am J Kidney Dis. 2018 May;71(5):605-607.

\section{ORCID}

Ana Farinha iD 0000-0002-5402-7626

\section{Correspondence to:}

Ana Farinha, MD

E-mail: alpfarinha@gmail.com 